\title{
Ion Transport Phenomena Across an Ion-Exchange Membrane
}

-Multi-Ionic System-

\author{
Kiyotoshi InEnAGA ${ }^{1}$, Tetsuhiro SAKAE ${ }^{2}$ and Hideo KimizuKA ${ }^{2}$ \\ ${ }^{1}$ Department of Physiology, School of Medicine, University of Occupational and Environmental \\ Health, Japan. Kitakyushu 807, Japan \\ ${ }^{2}$ Department of Chemistry, Faculty of Science, Kyushu University. Fukuoka 812, Japan
}

\begin{abstract}
By use of ion-exchange membrane CK-1, 0.3 t, the transient responses of membrane potential and interdiffusional flux from the non-steady state to quasi-steady state in the multi-ionic system were studied. Some interesting transient phenomena of the membrane potentials were observed under certain conditions. All modes of the responses were qualitatively explained in terms of the diffusion coefficients and the affinity of ions to the membrane. It was proved experimentally that in the transient process, the time lag of the membrane potential to attain the quasi-steady state was nearly equal to that of the flux. Next the membrane potentials in the steady state were estimated by extrapolation and then the apparent transport numbers were calculated. It was shown that the apparent transport numbers estimated from the membrane potentials agreed with the transport numbers calculated according to non-equilibrium thermodynamics.
\end{abstract}

Key words: multi-ionic system, ion exchange membrane, transient phenomena, steady state, transport number.

(Received 14 February 1981)

\section{Introduction}

When a charged membrane separates two solutions containing more than two electrolytes and consisting of different components, the interdiffusion of the counter-ions will take place and the membrane potential will be generated between the two solutions. This system is generally called a multi-ionic system.

In the study of the transport phenomena of ion across a membrane in a multi-ionic system, so far, the membrane phenomena such as the membrane potential, conductance, and flux have been confined to those only in the steady state (Scatchard \& Helfferich, 1956; Helfferich, 1956; Mackay \& Meares, 1959, 1960; Hale \& Govindan, 1969; Inenaga et al., 1977; Inenaga \& Yoshida, 1980; Inenaga \& Aso, 1981). Therefore, we feel it is valuable to examine the non-steady membrane phenomena in order to carry out a detailed investigation on the transport phenomena of ions across a membrane. The observed transient response of the membrane potential and the flux from the non-steady state to the quasi-steady state were studied in terms of the mobility of ion in the membrane and the affinity of ion to the membrane. Furthermore, the picture of ion transport across 
a membrane in the steady state was revealed in terms of the transport number.

\section{Experimental Section}

The membrane used was a cation exchanger of the sulfonic acid type, CK-1, $0.3 \mathrm{t}$, which was supplied by the Asahi Chemical Industry Co., Ltd. All chemicals were of analytical reagent grade and used without further purification. The experiments were carried out at $25 \pm 0.1^{\circ} \mathrm{C}$.

\section{A. Characteristics of membrane}

Prior to measurements, the membranes were equilibrated several times with $1.0 \mathrm{~N}$ hydrochloric acid and successively with $1.0 \mathrm{~N}$ sodium chloride. The Na-form membranes were stocked in $1.0 \mathrm{~N}$ sodium chloride solution according to Yamauchi \& Kimizuka (1971).

The membranes were thoroughly washed with distilled water in order to remove the Donnan salt, then immersed in either $0.1 \mathrm{~N} \mathrm{CaCl}_{2}$ or $0.1 \mathrm{~N} \mathrm{NaCl}$, and again washed thoroughly with distilled water. The membrane thickness was measured with a micrometer. The a. c. conductivity of the membrane was measured with a mercury electrode connected to a Yokogawa-Hewlett-Packard Universal Bridge at $1000 \mathrm{~Hz}$ (Subrahmanyan \& Lakshminarayanaiah, 1968). Then the mobilities of $\mathrm{Ca}$ and $\mathrm{Na}$ ions in the membrane were calculated. The results are shown in Table 1 . The cross sectional area of the membrane in the conductance measurement was $0.785 \mathrm{~cm}^{2}$.

The ion-exchange capacity was measured by the titration of hydrogen ions after treating the membrane of the hydrogen ion form with an excess of $1 \mathrm{~N} \mathrm{NaCl}$ solution. The result is also shown in Table 1 in terms of equivalent in the membrane.

The corrected molar selectivity coefficient, $K_{a}^{\prime} \mathrm{Ca}$, was obtained in the following way. The total equivalent concentration of the solution was held at $0.1 \mathrm{~N}$ for all the ion-exchange experiments. The membrane was immersed in a large volume of solution consisting of a given composition of $\mathrm{NaCl}$ and $\mathrm{CaCl}_{2}$ and the system was stirred for five days. (By preliminary experiments it was revealed that the ion-exchange equilibrium was almost attained within a day.) Thereafter, the membranes were taken out from the solutions, blotted with filter paper, and then soaked in $4 \mathrm{~N} \mathrm{CaCl}_{2}$ solution. Since the membrane is immersed in a very concentrated calcium chloride solution, it is considered that sodium ions in the membrane are completely replaced by calcium ions. (The concentration of sodium ions in the bulk solution was less than $10^{-2} \mathrm{~N}$ as a result of ion-exchange equilib-

Table. 1. Membrane properties

\begin{tabular}{lcc}
\hline & Na-form & Ca-form \\
\hline Thickness $(\mathrm{cm})$ & $3.39 \times 10^{-2}$ & $3.37 \times 10^{-2}$ \\
Mobility $\left(\mathrm{cm}^{2} / \mathrm{sec} \cdot \mathrm{V}\right)$ & $2.22 \times 10^{-5}$ & $8.22 \times 10^{-6}$ \\
Ion-exchange capacity (equiv $/ \ell)$ & & 1.52 \\
\hline
\end{tabular}


rium.) All samples were analyzed for sodium ions with a flame photometer (EKO Instruments Trading Co., Ltd. Model FAN).

B. Membrane potentials and fluxes

The cell for measurement of membrane potentials and interdiffusional fluxes was the same as in a previous paper (Inenaga \& Yoshida, 1980). In this study a stirring rate was kept at 100 r.p. m.

After the membranes were conditioned in the same way as in the measurement of the ion-exchange selectivity, they were mounted in the cell and the membrane potentials and the fluxes were measured. Then the compartment (") was filled with the same solution as employed for conditioning the membrane. (In these experiments, the total equivalent concentration of the solutions was also $0.1 \mathrm{~N}$.) The solution of different composition was rapidly poured into the compartment ('). Immediately, the time-course of the membrane potential was measured with $\mathrm{Ag} / \mathrm{AgCl}$ electrodes connected to a digital multimeter (Takeda Riken Co., Ltd. Model TR-6856). The interdiffusional fluxes were measured in two systems, $\left(X_{\mathrm{Na}}^{\prime}=0.00 \mid\right.$ membrane $\left.\mid X_{\mathrm{Na}}^{\prime \prime}=1.00\right)$ and $\left(X_{\mathrm{Na}}^{\prime}=1.00 \mid\right.$ membrane $\mid$ $\left.X_{\mathrm{Na}}^{\prime \prime}=0.00\right)$. Henceforth, for simplicity the system $\left(X_{\mathrm{N} a}^{\prime}=0.00 \mid\right.$ membrane $\left.\mid X_{\mathrm{Na}}^{\prime \prime}=1.00\right)$ will be abbreviated as $\left(X_{N_{a}^{\prime}}^{\prime}=0.00 \mid X_{N^{\prime \prime}}^{\prime \prime}=1.00\right)$. At certain time intervals such as $5,10,20$, 30,40 and 60 minutes, the solutions were taken out of the cell and analyzed for sodium and calcium ions by a flame photometer.

\section{Results and Discussion}

A. Ion-exchange equilibrium

The difference in affinities of two counter-ions, $A$ and $B$, in the membrane can be

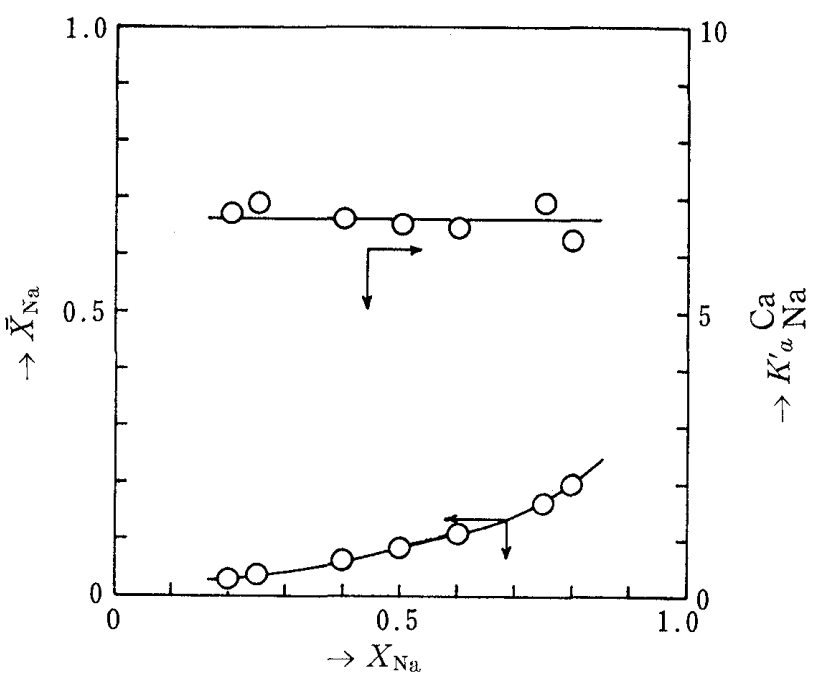

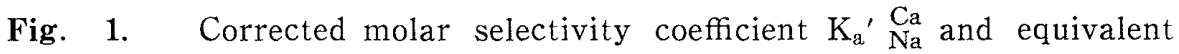
fraction of sodium ion in the membrane $\overline{\mathrm{X}}_{\mathrm{N}_{a}}$ against equivalent fraction of bulk solution $\mathrm{X}_{\mathrm{Na}}$. 


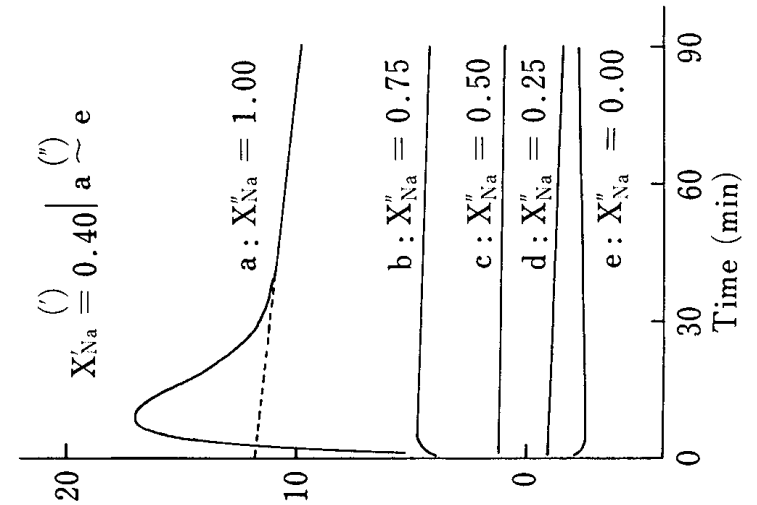

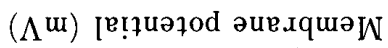

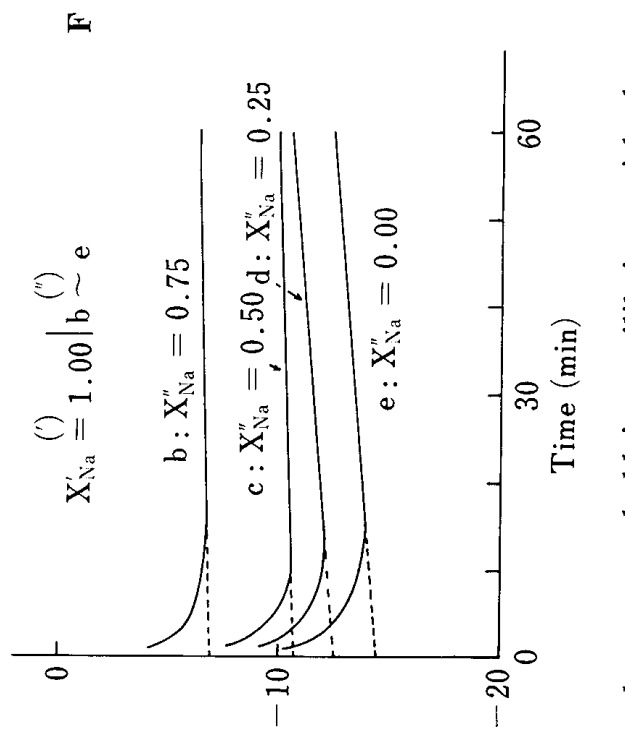

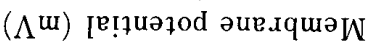

$\cong$

폰

吾

守

$\Xi$

흥 응

芯

苂 $\stackrel{.}{\Xi}$

है ठ․

品

点

田
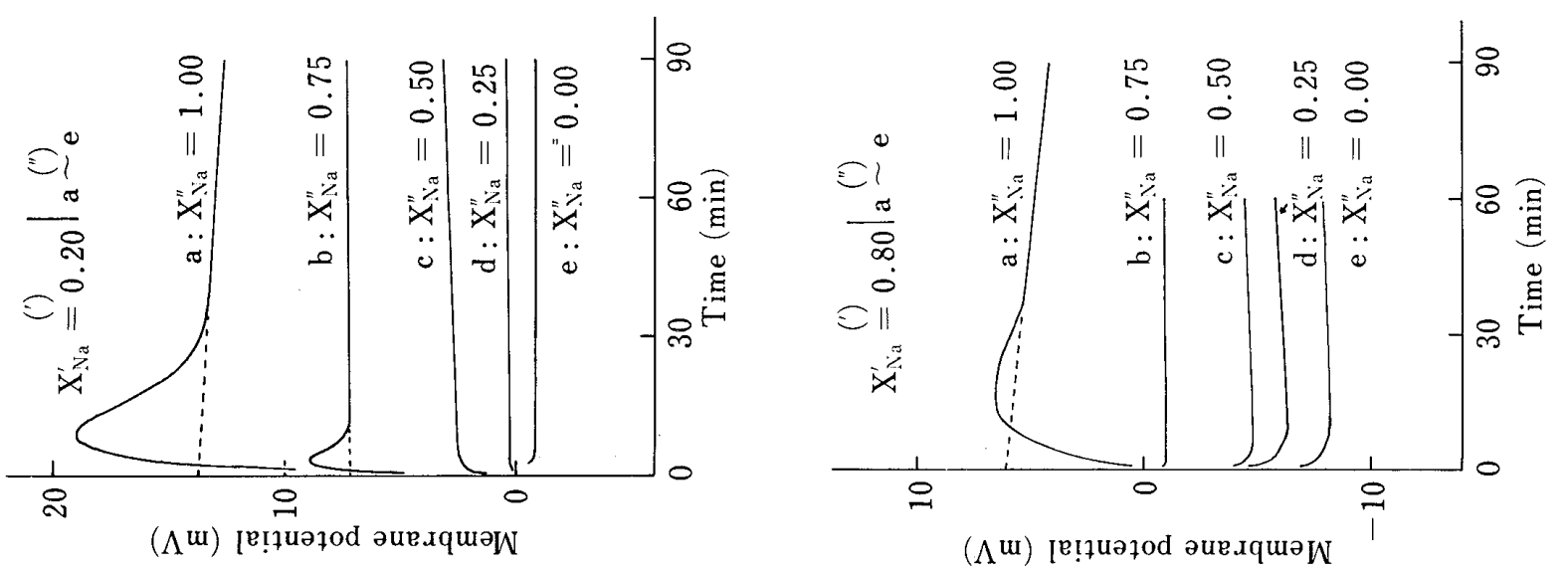

हึ

告

का

$\dot{4}$

\&.

ㄴ.

t웅

.

㡙

䓌蚂

矛㟧

동

氙
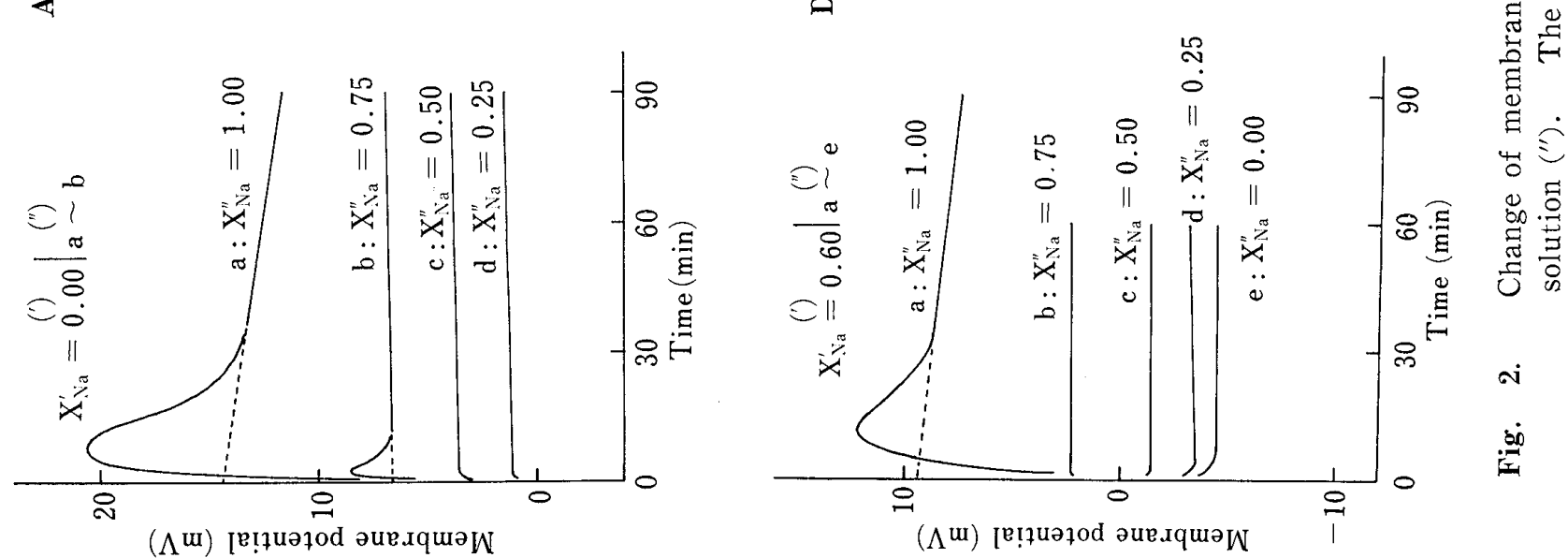
determined by the measurement of an ion-exchange equilibrium. For the ion-exchange equilibrium between the counter-ions, $A$ and $B$, we have

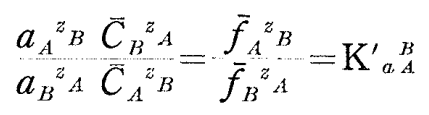

where

$$
z_{A} \bar{C}_{A}+z_{B} \bar{C}_{B}=\bar{C}
$$

and $C$ is the molarity, $a$ the activity, $f$ the activity coefficient, $z$ the valency, and $K_{a A}^{\prime}$ the corrected molar selectivity coefficient. $K_{a A}^{\prime}$ represents the selectivity of one counterion $B$ relative to the other counter-ion $A$. Superscript bars refer to the membrane phase. If $a_{\mathrm{Na}}, a_{\mathrm{Ca}}, \bar{C}_{\mathrm{Na}}$, and $\bar{C}$ are known for the ion-exchange reaction, $\mathrm{Na}+\mathrm{Ca} \rightleftarrows \mathrm{Na}+\mathrm{Ca}, K_{a}^{\prime} \mathrm{Na}$ can be estimated from eq. (1). The selectivity coefficients are shown in Fig. 1 where they are plotted versus equivalent fraction of sodium ions in the bulk solution, $X_{\mathrm{Na}}$. The value of $K_{a}^{\prime} \mathrm{Ca}$ is almost constant, $6.64 \pm 0.37$, within the concentration range studied. Hence, it is seen that the membrane is more selective to calcium ions than to sodium ions. The equivalent fraction of sodium ions in the membrane, $\bar{X}_{\mathrm{Na}}$, against the sodium equivalent fraction of bulk solution is also shown in Fig. 1. This supports the previous understanding that the counter-ion of higher charge is more strongly bound to the ion exchanger. (Kressman \& Kitchener, 1949; Meares \& Thain, 1968)

\section{B. Non-steady state}

The time-courses of the membrane potentials are shown in Fig. 2. Total equivalent concentration in each compartment is $0.1 \mathrm{~N}$. The composition of each solution is described in terms of an equivalent fraction of sodium ion, $X_{\mathrm{Na}}$. Since the $\mathrm{Ag} / \mathrm{AgCl}$ electrode is used for the potential measurement, the membrane potentials are given by subtraction of the electrode potential from the electromotive force. The sign of the potential refers to the double primed compartment. In the curves a of Fig. $2 \mathrm{~A}-\mathrm{F}$ and the curves $\mathrm{b}$ of Fig. $2 \mathrm{~A}$ and $\mathrm{B}$, it is interesting to note that transient convex-shaped potentials were observed at the initial stage of the time-courses of the membrane potentials. The convexshaped potential height is the greatest at the system $\left(X_{\mathrm{N} a}^{\prime}=0.00 \mid X_{\mathrm{Na}}^{\prime \prime}=1.00\right)$ and decreases gradually with the decrease in calcium ions of the solution $\left({ }^{\prime}\right)$. On the other hand, as can be seen in the typical curve e of Fig. $2 \mathrm{~F}$, the convex-shaped potential does not appear

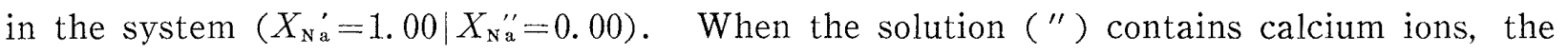
convex-shaped potential can not be seen except for the systems $\left(X_{\mathrm{N} a}^{\prime}=0.00 \mid X_{\mathrm{Na}}^{\prime \prime}=0.75\right)$ and $\left(X_{\mathrm{N} a}^{\prime}=0.20 \mid X_{\mathrm{N}}^{\prime \prime}=0.75\right)$. Thus the occurrence of the convex-shaped potential depends on the composition of the solution (') and the membrane. From the ion-exchange isotherm shown in Fig. 1, we know that $\bar{X}_{\mathrm{Na}}$ is less than 0.2 when $X_{\mathrm{Na}}$ is less than 0.8 (the membrane has a strong tendency to accumulate calcium ions). Therefore, it is suggested that the convex-shaped potential at the early stage of the time-course of the membrane potential may be caused by the rapid exchange of sodium ions in the membrane for calcium 
ions in the bulk solution. Though calcium ions in the membrane are initially present in two systems, $\left(X_{\mathrm{Na}}^{\prime}=0.00 \mid X_{\mathrm{Na}}^{\prime \prime}=0.75\right)$ and $\left(X_{\mathrm{N} a}^{\prime}=0.20 \mid X_{\mathrm{Na}}^{\prime \prime}=0.75\right)$, the appearance of the convex-shaped potentials in these systems may be interpreted by considering that the composition of membrane tends to change rapidly into a more calcium-rich membrane. The abrupt increase of calcium ions at the membrane-solution interface may cause a large concentration gradient of calcium ions within the membrane. The convex-shaped potential height may be related to the concentration gradient of calcium ions at the interface. The large concentration gradient may be collapsed by interdiffusion and then the whole system becomes a quasi-steady state. On the other hand, the potential change with the time at the initial stage is also in a non-steady state in the systems where the convexshaped potentials do not appear.

The transient change in the membrane potential can be further clarified by the measurement of the ionic flux. When an ion-exchange membrane separates two solutions of different compositions, the interdiffusion of the counter-ions takes place. The counterions leave one solution for the membrane and then enter into another solution. The quantity of the counter-ions entering into another solution increases with time. Here, we are interested in relating the time-course of the flux with that of the membrane potential. In order to measure the net flux at a given time interval $\left(t^{\prime \prime}-t^{\prime}\right)$, the following procedure is profitable. The quantity of the counter-ion $\left(Q_{t^{\prime \prime}}-Q_{t^{\prime}}\right)$ flowing across a membrane in a given time interval is divided by $\left(t^{\prime \prime}-t^{\prime}\right)$ and a cross section $S$,

$$
J_{i}=\frac{\left(Q_{t^{\prime \prime}}-Q_{t^{\prime}}\right)}{S\left(t^{\prime \prime}-t^{\prime}\right)}
$$

where $J_{i}$ is taken as the flux at a time $\left(t^{\prime}+t^{\prime \prime}\right) / 2$. Fig. 3 shows the time-courses of the interdiffusional fluxes estimated in this way for the two systems, $\left(X_{\mathrm{Na}}^{\prime}=0.00 \mid X_{\mathrm{Na}}^{\prime \prime}=1.00\right)$ and $\left(X_{\mathrm{N} a}^{\prime}=1.00 \mid X_{\mathrm{N} a}^{\prime \prime}=0.00\right)$. The flux is plotted against a time $\left(t^{\prime}+t^{\prime \prime}\right) / 2$. For convenience, the former system will be termed system $A$ and the latter, system $B$. Curve 1 denotes the change of fluxes in system $A$ and curve 2 the change of fluxes in system $B$, respectively. From Fig. 3, it is seen that the fluxes of sodium and calcium ions in the two systems converge into the same value after a certain time. It is quite natural that these two systems reach the same quasi-steady state satisfying the condition, $J_{\mathrm{Na}}+2 J_{\mathrm{Ca}}=0$. On the other hand, it can be seen also in this figure that the two systems approach a quasi-steady state at different times. In system $A$, initially, the sodium ion flux is large and the calcium ion flux is small. The apparently large flux of sodium ions is mainly due to efflux of its ions by the abrupt ion-exchange. Since the calcium ions flux can not be detected until the calcium ions actually pass through the membrane, the calcium ion flux seems to be small at the initial stage. The mode of fluxes in system $B$ can be interpreted in a similar way, as in system $A$. However the values of the four fluxes are appreciably different before the quasi-steady state is reached. The fact that, at the initial stage, $\left|J_{\mathrm{Na}}\right|$ in system $\mathrm{A}$ is greater than $2\left|J_{\mathrm{Ca}}\right|$ in system $\mathrm{B}$ can be explained by the different affinities of sodium and calcium ions to the membrane. (Though, the calcium 


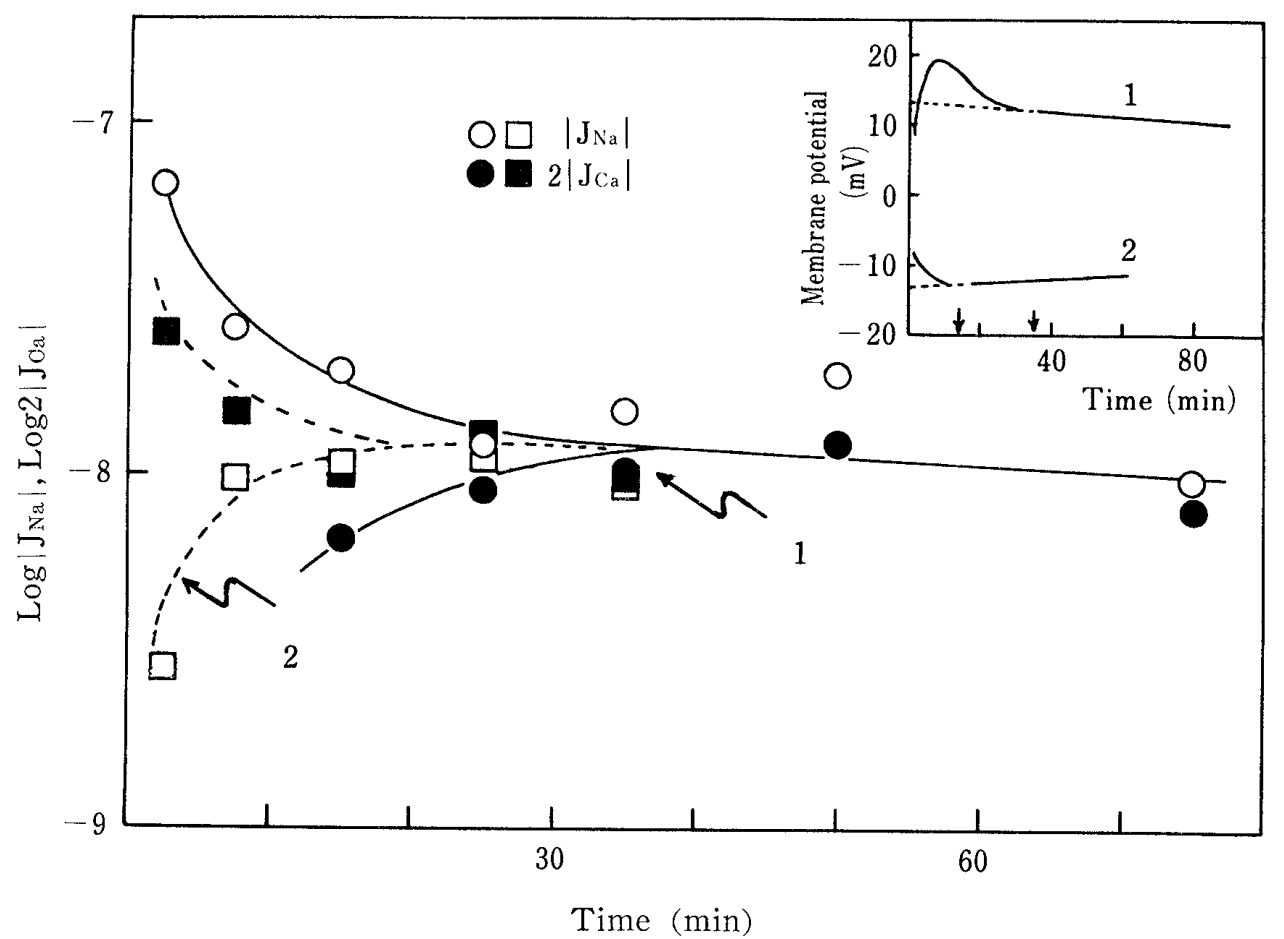

Fig. 3. Change of ion flux with time. For the first time the membrane was held in equilibrium with the solution $\left({ }^{\prime \prime}\right)$. The solution of different compositions was rapidly poured into the compartment ('). The time-courses of membrane potentials in the two systems are inserted. Curve 1 denotes the change of fluxes in the system of $\left(\mathrm{X}_{\mathbb{N} i l}{ }^{\prime}=0.00 \mid \mathrm{X}_{\mathbb{N} i l}{ }^{\prime \prime}=1.00\right)$ and curve 2 the change of fluxes in the system of $\left(\mathrm{X}_{\mathrm{Na}: \mathrm{i}}{ }^{\prime}=1.00 \mid \mathrm{X}_{\mathrm{Na}}{ }^{\prime \prime}=0.00\right)$.

ions in system $B$ are rapidly exchanged for the sodium ions, the exchanged quantity is small compared with the sodium ions in system A.)

The time-courses of membrane potentials in the two systems are inserted into Fig. 3 for comparison with those of the fluxes. In both $\mathrm{A}$ and $\mathrm{B}$ systems, the times when both the fluxes and the membrane potentials reach a quasi-steady state are nearly equal. The time for system $\mathrm{A}$ is about $35 \mathrm{~min}$ and that for system $\mathrm{B}$ about $18 \mathrm{~min}$. The time-courses of the membrane potentials for the system, $(\mathrm{NaCl} \mid \mathrm{KCl})$, were described in Inenaga (1979). The experiment was performed in the same way as the present system. The membrane potentials reached quickly the quasi-steady state after a short time interval of non-steady state (less $5 \mathrm{~min}$ ). It is of interest that the transient process of system $(\mathrm{NaCl} \mid \mathrm{KCl})$ is very different from the present system $\left(\mathrm{NaCl} / \mathrm{CaCl}_{2}\right)$.

The dominant factors in the ion transport phenomena through the membrane must be the diffusion velocity of ions and the ionic affinity to the membrane. The diffusion coefficients of sodium and potassium ions are nearly equal and the corrected molar selectivity coefficient $K_{a}^{\prime} \mathrm{Ka}$ is almost equal to one (Inenaga \& Yoshida, 1980). However, the diffusion coefficients of sodium and calcium are very different and $K_{a}^{\prime} \mathrm{Na}=6.64$. Owing to the 
difference in the ratio of the diffusion coefficients and the selectivity to the membrane, the different transient processes in these two systems could be observed.

\section{Steady state}

All the membrane potentials change almost linearly with time in the quasi-steady state. In this period, the composition of each bulk solution is more or less varying from the original one by the interdiffusion of the counter-ions across the membrane. Extrapolating the potential versus time to zero time, one can obtain the steady membrane potential of the system in which the composition of each bulk solution is the same as the initial one. The steady membrane potentials thus obtained are shown in Fig. 4. Six curves for the steady membrane potentials against equivalent fraction of sodium ions in solution ("), $X_{\mathrm{Na}}^{\prime \prime}$, show similar shifts with the concentration dependence.

Now let us discuss the steady membrane potentials obtained by the extrapolation. Since the total membrane current is determined by the sum of the ionic currents (In this study the total membrane current is zero. However, eq. (4) holds regardless of either the presence or the absence of electric current.), we have (Kimizuka, 1977)

$$
I=\Sigma i_{\alpha}=\Sigma z_{\alpha} F J_{\alpha}=-G_{m}\left(V-V_{o}\right)=-\Sigma g_{\alpha}\left(V-V_{\alpha}\right)
$$

where

$$
\begin{aligned}
& g_{\alpha}=t_{\alpha} G_{m}, \\
& V_{o}=\Sigma t_{\alpha} V_{\alpha}, \\
& \Sigma t_{\alpha}=1,
\end{aligned}
$$

and $G_{m}$ is the membrane conductance, $\left(V-V_{\alpha}\right)$ the driving potential difference for ion $\alpha$,

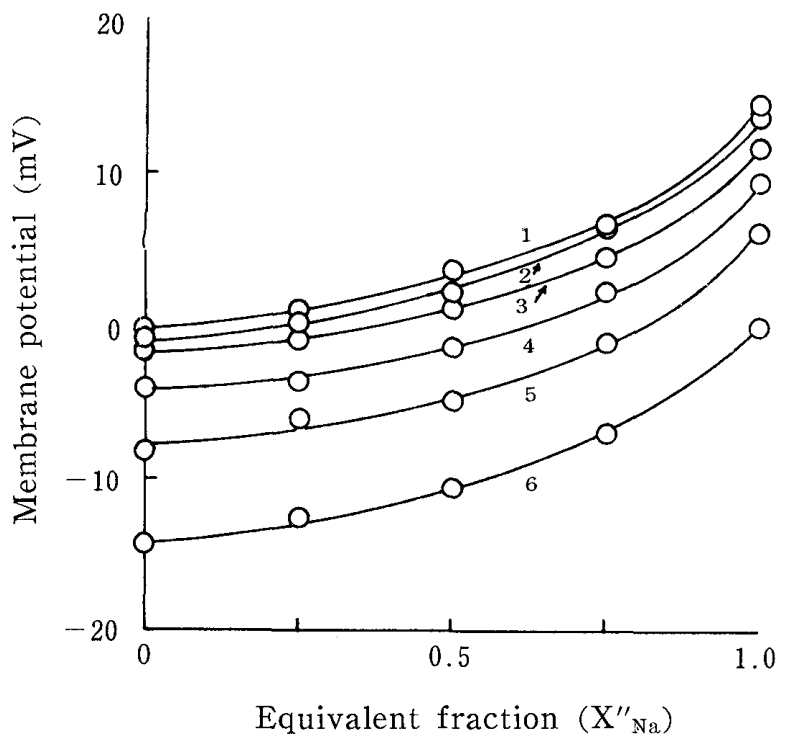

Fig. 4. Steady membrane potential against equivalent fraction of sodium ions in the solution ("), $\mathrm{X}_{\mathrm{Na}}{ }^{\prime \prime}$. Curves $1,2,3,4,5$ and 6 represent membrane potentials at $\mathrm{X}_{\mathrm{Na}}{ }^{\prime}=0.00,0.20$, $0.40,0.60,0.80$ and 1.00 , respectively. 
$V_{o}$ the membrane potential at the zero membrane current, $t_{\alpha}$ the apparent transport number, $V_{\alpha}$ the equilibrium membrane potential, Faraday constant, respectively

$$
z_{\alpha} F V_{\alpha} / R T=\ln a_{\alpha}^{\prime} / a_{\alpha}^{\prime \prime}
$$

where $a_{\alpha}$ denotes the activity of ion $\alpha . \quad$ The steady membrane potentials in the systems where the solutions of two compartments contain both calcium and sodium ions can be obtained from eq. (6) as follows;

$$
V_{o}=t_{\mathrm{Na}} V_{\mathrm{Na}}+t_{\mathrm{Ca}} V_{\mathrm{Ca}}+t_{\mathrm{Cl}} V_{\mathrm{Cl} 1}
$$

Here, it is assumed that the effects of the film layer is small or negligible and two solution-membrane interfaces are close to equilibrium. Since total concentrations of chloride ions in solutions (') and (") are the same and the concentration of co-ions within the membrane is almost negligible, (Kaibara et al., 1973)

$$
V_{\mathrm{Cl}}=-(R T / F) \ln \left(a_{\mathrm{C} i}{ }^{\prime} / a_{\mathrm{C}}^{\prime \prime}\right) \simeq 0
$$

and

$$
t_{\mathrm{Cl}} \simeq 0 \text {. }
$$

Then eq. (9) is reduced to

$$
V_{o}=t_{\mathrm{Na}} V_{\mathrm{Na}}+\left(1-t_{\mathrm{Na}}\right) V_{\mathrm{Ca}} \text {. }
$$

From eq. (12) we obtain the transport number of sodium ion, $t_{\mathrm{Na}}$. The values are shown in Table 2. In the absence of co-ions, the transport number of one ionic form membrane is equal to one, that is, $t_{\mathrm{Na}}=1$ or $t_{\mathrm{Ca}}=1$. Table 2 shows that the transport number of sodium ion increases with the increase in the sodium fraction of the bulk solution. Taking into account the result shown in Fig. 1 , it is seen that the increase of $t_{\mathrm{Na}}$ is closely related to the increase of the sodium fraction in the membrane.

According to the non-equilibrium thermodynamics (Kirkwood, 1954), the ion flux is given by

Table 2. Transport number

\begin{tabular}{ccccc} 
& \multicolumn{3}{c}{$\mathrm{X}_{\mathrm{Na}}{ }^{\prime}$} \\
& 0.2 & 0.4 & 0.6 & 0.8 \\
\hline \multirow{2}{*}{0.25} & 0.08 & 0.12 & 0.13 & 0.21 \\
& 0.07 & 0.12 & 0.16 & 0.21 \\
0.50 & 0.11 & 0.12 & 0.17 & 0.27 \\
\multirow{2}{*}{0.75} & 0.12 & 0.17 & 0.22 & 0.29 \\
& 0.15 & 0.22 & 0.30 & 0.38 \\
& 0.18 & 0.24 & 0.30 & 0.37 \\
\hline
\end{tabular}

There are $\mathrm{X}_{\mathrm{Na}}{ }^{\prime}$, equivalent fractions of sodium ions of solution ('), in the section (1) and $\mathrm{X}_{\mathrm{Na}}{ }^{\prime \prime}$, ones of solution("), in the left column.

The transport numbers in the upper and lower rows of sections (2), (3) and (4) are calculated according to eqs. (12) and (23), respectively. 


$$
J_{\alpha}=-\sum_{\beta} l_{\alpha \beta} \Gamma \tilde{\mu}_{\beta}
$$

where $l_{\alpha \beta}$ is the phenomenological coefficient and $\tilde{\mu}_{\beta}$ the electrochemical potential. Since the cation exchange membrane is used and the solution phases are equal normality in the present study, we assume that fluxes of solvent and chloride ions are insignificant and hence eq. (13) is reduced to (Kimizuka, 1977)

$$
J_{\alpha}=\bar{D}_{\alpha} \bar{C}_{\alpha} \sigma \tilde{\mu}_{\alpha} / R T
$$

where $\alpha$ refers to either calcium or sodium ion. The electrochemical activity is assumed to be continuous in the over-all system. Integrating eq. (14) with respect to $x$, we obtain

$$
\tilde{\mu}_{\alpha}^{\prime \prime}-\widetilde{\mu}_{\alpha}^{\prime}=\tilde{\mu}_{\alpha}^{b}-\widetilde{\mu}_{\alpha}^{a}=\Delta \tilde{\mu}_{\alpha}=-\bar{J}_{\alpha} \int_{a}^{b} \frac{R T}{a \bar{D}_{\alpha} \bar{C}_{\alpha}} d x
$$

or

$$
\overline{J_{\alpha}}=-l_{\alpha} \Delta \tilde{\mu}_{\alpha}=-z_{\alpha} F l_{\alpha}\left(V-V_{\alpha}\right)
$$

where

$$
l_{\alpha}^{-1}=\int_{a}^{b} \frac{R T}{a_{\bar{D}} \bar{C}_{\alpha}} d x
$$

and the limits of integrations $a$ and $b$ represent the positions of the two membrane-solution interfaces. Combining eqs. (4), (5) and (16), we obtain

$$
t_{A}=\frac{g_{A}}{t_{B}}=\frac{z_{A}{ }^{2} l_{A}}{z_{B}{ }^{2} l_{B}}
$$

where the subscripts $A$ and $B$ refer to sodium and calcium ions, respectively. Here $\bar{J}_{\mathrm{Cl}}$ is assumed to be zero. (In a bi-ionic system, $(0.1 \mathrm{~N} \mathrm{NaCl} \mid$ membrane CK-1 $1.0 \mathrm{t} \mid 0.1 \mathrm{~N}$ $\mathrm{CaCl}_{2}$ ), Inenaga \& Aso (1981) have obtained the result that $2\left|J_{\mathrm{Ca}}\right|$ agreed with $\left|J_{\mathrm{Na}}\right|$ within an experimental error. Therefore, the assumption of $\bar{J}_{\mathrm{Cl}}=0$ may be considered to be reasonable.) If $\bar{D}_{\alpha}$ is constant in the membrane, eqs. (17) and (18) are written as

$$
l_{\alpha}^{-1}=\frac{R T}{\bar{D}_{\alpha}} \int \frac{b}{a} \bar{C}_{\alpha}
$$

and

$$
\frac{t_{A}}{t_{B}}=\frac{z_{A} \bar{D}_{A}}{z_{B} \bar{D}_{B}} \frac{\int_{a}^{b} d x / \bar{C}_{B}}{\int_{a}^{b} d x / \bar{C}_{A}}
$$

Assuming that the condition of the electroneutrality is held in the membrane, we have

$$
z_{A} \bar{C}_{A}+z_{B} \bar{C}_{B} \simeq \bar{C}=\text { const. }
$$

The condition of zero-electric current and eq. (21) lead

$$
I=z_{A} \bar{J}_{A}+z_{B} \bar{J}_{B}=0
$$

and 


$$
\frac{t_{A}}{t_{B}}=-\frac{z_{A}}{z_{B}} \frac{\ln \frac{\bar{C}_{B}^{b}}{\bar{C}_{B}^{a}-}-\frac{z_{B}\left(\bar{D}_{A}-\bar{D}_{B}\right)}{\left(z_{A} \bar{D}_{A}-z_{B} \bar{D}_{B}\right)} \ln \frac{z_{B}\left(\bar{D}_{A}-z_{B} \bar{D}_{B}\right) \bar{C}_{B}^{b}+z_{A} \bar{D}_{A} \bar{C}}{z_{B}\left(z_{A} \bar{D}_{A}-z_{B} \bar{D}_{B}\right) \bar{C}_{B}^{a}+z_{A} \bar{D}_{A} \bar{C}}}{\ln \bar{C}_{A}^{b}} \frac{z_{A}\left(\bar{D}_{A}-\bar{D}_{B}\right)}{\overline{\bar{C}}_{A}^{a}-} \ln \frac{z_{A}\left(z_{A} \bar{D}_{A}-z_{B} \bar{D}_{B}\right) \bar{C}_{A}^{b}+z_{B} \bar{D}_{B} \bar{C}}{\left(z_{A} \bar{D}_{A}-z_{B} \bar{D}_{B}\right)} \ln \frac{z_{A}\left(z_{A} \bar{D}_{A}-z_{B} \bar{D}_{B}\right) \bar{C}_{A}^{a}+z_{B} \bar{D}_{B} \bar{C}}{z_{B}}
$$

We can estimate the values of $\bar{C}_{A}^{a}, \bar{C}_{A}^{b}, \bar{C}_{B}^{a}$ and $\bar{C}_{B}^{b}$ from the data of ion-exchange equilibrium. Then, we can calculate $t_{A} / t_{B}$ from eq. (23) by the use of the following relation (Kumamoto \& Kimizuka, 1981) and ion concentrations at the membrane surfaces.

$$
z_{A} \bar{D}_{A} / z_{B} \bar{D}_{B}=\bar{u}_{A} / \bar{u}_{B}
$$

where $u$ denotes the mobility.

In Table 2, the transport numbers calculated from eqs. (7) and (23) are compared with those from eq. (12). The agreement between these transport numbers is excellent. Hence, the steady membrane potential for the system in which each compartment contains two counter-ions is predictable according to eq. (12) by the use of the transport number calculated from eq. (23).

\section{References}

Hale, D. K. \& Govindan, K. P. (1969): Phosphonic acid cation-exchange membranes. J. Electrochem. Soc., 116: 1373-1381.

Helfferich, F. (1956): Bi-ionic potentials. Discuss. Faraday Soc., 21: 70-82.

Inenaga, K. (1979): Study of ion transport through ion exchange membrane. Doctoral thesis. Kyushu Univ., Fukuoka.

Inenaga, K. \& Aso, Y. (1981): Effect of a film layer on mono-divalent bi-ionic membrane potential. J. Mem. Sci. (in press)

Inenaga, K., Yamauchi, A. \& Kimizuka, H. (1977): A study of the transport of tetraalkylammonium ions through ion-exchange membranes. Bull. Chem. Soc. Jpn., 50: 2584-2588.

Inenaga, K. \& Yoshida, N. (1980): Effect of an unstirred layer on ion transport through a membrane. J. Mem. Sci., 6: 271-282.

Kaibara, K., Saito, K. \& Kimizuka, H. (1973): Self-diffusion of a cation through cation exchange membrane and membrane permeability. Bull. Chem. Soc. Jpn., 46: 3712-3714.

Kimizuka, H. (1977): Nonequilibrium thermodynamics of ion transport through membranes. Membrane, 4: 255-265.

Kirkwood, J. G. (1954): Transport of ions through biological membranes from the standpoint of irreversible thermodynamics. In: Ion Transport across a Membrane. Academic Press, New York. p. 119.

Kressman, T. R. E. \& Kitchener, J. A. (1949): Cation exchange with a synthetic phenolsulphonate resin. Part I, II \& III. J. Chem. Soc., 1190-1210.

Kumamoto, E. \& Kimizuka, H. (1981): Transport properties of the barium form of a poly (styrene sulfonic acid) cation-exchange membrane. J. Phys. Chem. (in press)

Mackay, D. \& Meares, P. (1959): On the correction for unstirred solution films in ion-exchange membrane cells. Kolloid Z., 167: 31-39.

Mackay, D. \& Meares, P. (1960): Ion-exchange across a cationic membrane in dilute solutions. Kolloid Z., 171: 139-149.

Meares, P. \& Thain, J. F. (1968): The thermodynamics of cation exchange. J. Phys. Chem., 72: 2789-2797. 
Scatchard, G. \& Helfferich, F. (1956): The effect of stirring on cells with cation exchanger membranes. Discuss. Faraday Soc., 21: 70-82.

Subrahmanyan, V. \& Lakshminarayanaiah, N. (1968): A rapid method for the determination of electrical coductance of ion-exchanger membranes. J. Phys. Chem., 72: 4314-4316.

Yamauchi, A. \& Kimizuka, H. (1971): Study of bi-ionic potentials. J. theor. Biol., 30: $285-295$.

イオンのイオン交换膜透過現象

一多種イオン系一

稲 永 清 敏 ${ }^{1}$. 栄哲 浩 ${ }^{2}$. 君 塚 英 夫 $^{2}$

1産業医科大学第一生理学教室 2 九州大学理学部化学教室

要旨： イオン交換膜 $(\mathrm{CK}-1,0.3 \mathrm{t})$ を用いて多種イオン系における膜電位と相互拡散流束の非定 常状態方ら定常状態への過渡現象について研究した。膜電位の興味ある過渡現象は，イ才 ンの拢散係数と膜に対するイオンの親和性によって定性的に説明された．また，膜電位と 流束の準静的定常状態に達するまでの時間はほぼ等しいことが皮験的に示された。さらに 定常状態膜電位加ら求められた輸率は非平衡の熱力学に従って算出された輸率と等しいと とが示された。

J, UOEH（產鄴医大誌)，3 (2)：97-108 (1981) 